\title{
CONFERENCE PROGRAMME
}

\author{
Thursday 3 May 2001
}

\section{Plenary}

Professor Edward H Shortliffe

Professor and Chairman, Department of Medical Informatics, Columbia University, New York City Networking Health: Prescriptions for the Internet

\section{Dr Astrid van Ginneken}

Erasmus University, Rotterdam, The Netherlands

Pros and cons of medical record structures for capture, consultation and extraction of patient data

\section{Dr Heather Heathfield}

Manchester University, Senior Consultant IT Perspectives Ltd

The Evaluation of Clinical Decision Support Systems

\section{$\underline{\text { Scientific Sessions }}$}

Medical Informatics

Modelling of the Visual Sleep Stage Scoring Procedure by a Modular Algorithm Based on Elements of Artificial Intelligence - Artisana

Matthias Schwaibold, B Scholler, T Penzel, A Bolz

Evaluating the Accuracy of Intelligent Systems Designed For Medicine

Ann E Smith, Sally McClean, Chris Nugent

Intelligent Algorithm to Counting and Classification of Cells

Allan De Medeiros Martins, A D N Duarte, A M Brito, A Sales, S Jane

Building Bayesian Belief Networks to Express the Cause and Effect Relationship for Dietary Intake and Pregnancy

Roy Sterrit, D A Bell, A H Marshall, A Moore, P R Flatt, M J Eaton-Evans, D Mccance

Predicting Patient Survival Using Bayesian Belief Networks

Adele Marshall, S I Mcclean, P H Millard, C M Shapcott

An Internet-Based Project All-Net: Technology Of Scientific Collaboration

Alexander Martynenko, Xavier Pastor, Dominique Biarent, Francis Leclerc, Oleg Medvedev, Joan Iglesias, Joseph Di Carlo 
Tissue Engineering and Artificial Organs

Artificial Myocardial Tissue (AMT); A Novel Contractile Engineered Heart Muscle

Theo Kofidis, MD, P Akhyari, U Martin, J Boublik, P Theodorou, A Ruhparwar, T Kraft, H P Kubis, B Brenner, G Gros, A Haverich

Development of Pulsatile Bioreactor for the in vitro formation of tissue engineered heart valves Kris Dumont, P Segers, S Vandenberghe, B Meuris, J Yperman, W Flameng, P Verdonck

Endothelialization of cardiovascular grafts Polydimethylsiloxane content affects adhesion and growth of endothelial cells onto polyurethane grafts

Giorgio Soldani, E Briganti, P Losi, I Martinelli

Characterisation of cardiac assist devices

Stijn Vandenberghe, P Segers, D De Wachter, P Verdonck

Hemodynamic aspects of Ventricle Assist Device

Idit Avrahami, S Einav, M Rosenfeld, K Affeld

Flow Visualization - Experiments with a geometrically-optimised vortex blood pump

Clare E Canal, A M Anderson, J R Shanebrook

Medical Imaging 1

Machine vision and texture analysis for the automated identification of tissue pattern in prostatic neoplasia

James Diamond, Neil H Anderson, Peter H Bartels, Rodolfo Montoroni, Peter W Hamilton

List-Mode Iterative Reconstruction for SPECT

Luc Bouwens, M Koole, Y D'Asseler, S Vanderberghe, R Van de Walle, I Lemahieu

Segmentation of Hippocampus From MR Images Using Geometric Models

Jan Klemencic, MSC, Vojko Valencic, Nuška Pecaric

Skull smearing effect on event related potentials investigated with a resistor mesh model

Xavier Franceries, B Doyon, B Rigaud, J P Morucci, P Celsis, B Doyon

Three-dimensional geometric sensitivity correction in triple-headed gamma camera coincidence

imaging: Separability properties

Yves D'Asseler, Stefaan Vandenberghe, Michel Koole, L R Bouwens, Rik Van de Walle, Ingace

Lemahieu, Rudi A Dierckx

Correction for the varying detection efficiency in gamma camera based coincidence detection

Steffan Vandenberghe, Y D'Asseler, R Van De Walle, I Lemahieu, R A Dierckx

Computers in Medicine

Animated Uroembryology: The millennium modality

H C Godbole, J P Hermon, T H Lynch

A Labview Program for measuring Auditory Evoked Potentials

J M Jimenez-Martínez, F J Gil ,J Roca, J A Alvarez 
First clinical experience with a personalised titanium membrane for bone reconstruction in tumour surgery

Veerle Pattijn, I Samson, J Vander Sloten, R Van Audekercke, B Swaelens, V De Buck

The Application of Pressure Mapping Techniques to Evaluate Commercially Available Pressure Relief Cushions

May Stinson, Alison Porter-Armstrong

Introducing a Clinical Information System: Re-engineering Patient Care in Cardiac Surgery

Fran Hegarty, Gery Boyle, Mary O'Connell, Barry Fanning, Kate Bentley, Tom Ryan,

Ailish McGovern

Biomaterials

Determination of the Quality of Calcium Phosphate Bioceramics

Adrian Boyd, M Akay, B J Meenan

Modification of medical implants by plasma immersion ion implantation

Robert Sader, S Mändl, D Krause, H F Zeilhofer, G Thorwarth, B Raushenbarch

The effects of sub optimal doses of mitomycin $C$ on transitional cell carcinoma

H C Godbole, T H Lynch, N H Anderson, S R Johnston, P F Keane, P W Hamilton, K Arthur,

K E Williamson

The role of electrical properties and surface energy on the biocompatibility and haemocompatibility of Si-DLC films

Thomas Okpalugo, A Ogwu, P Maguire, J McLaughlin

Control of Surface Morphology in Calcium Phosphate Thin-Films Deposited by Sputter Deposition

Brian J Meenan, M Akay, A Boyd

\section{Medical Imaging 2}

Multidimensional Images of Medical Data by Mathematical Registration Methods

Wolfgang Hauck, H F Zeilhofer, Z Krol, E Keeve, R Sader, K H Hoffmann, C Ganter, E Rummeney, N Avril, M Schwaiger

Detection of Glutathione in the Human Brian in vivo by Means of Double Quantum Coherence

Magnetic Resonance Spectroscopy

Dieter Meier, P Boesiger, U Dydak

Study of the Quantification of FBP ECT Images with a correction for partial volumn effects

Michel Koole, R Van de Walle, K Van Laere, Y D'Asseler, S Vandenberghe, I Lemahieu, R A

Dierckx, L R Bouwens

An Interpolation of RI Image by Means of $2 D$ Interpolating Digital Filter

Janusz Pawel Kowalski

Image Processing in Artificial Human Vision Systems

Justin Boyle, Anthony Maeder, Wageeh Boles 
Friday 4 May 2001

\section{Plenary}

Prof Shankar Subramaniam

University of California, San Diego

Bioinformatics: At the Crossroads of Biology, Engineering and Medicine

Professor Jan H van Bemmel

Erasmus University, Rotterdam, The Netherlands

Computer Interpretation of the ECG: Representation for Decision Support in Medicine

\section{Professor J McC Anderson}

University of Ulster, Northern Ireland

Cardiac Mapping as an Effective Tool in the Early Diagnosis of Acute Myocaridal Infarction

\section{$\underline{\text { Scientific Sessions }}$}

Technology for Assessment and Homecare

Application of Image Analysis to Detection of Tubercle Bacilli in Stained Human Sputum Patrick Felle, D Fitzgerald, T Murray, P Dervan, D O'Shea

Ultrasonic Velocity of Uterine Tumours

V R Singh, Kirti (Ghandhi) Bhatia

Assessment of Leg Ulcer Color Images Through Digital Image Processing

Andres Anobile Perez, Adilson Gonzaga

Development of a multimedia software application to help carers cope with caring problems

Mary Chambers, S Connor, M McGonigle, M Diver

Technology to enhance the quality of life of family carers: the ACTION project

Lennart Magnusson, M Chambers, H Berthold, E Hanson, L Brito, T Daly

An IT Approach to the Control and Management of Medication in the home; Requirements Analysis

Chris Nugent, N D Black, P Fiorini

Biosignals, Biosensors and Bioinformatics

Solving the direct problem of a nonlinear impedance equivalent circuit model

Jacques Jossinet, Eric T McAdams

Nonlinear Dynamics - From Conformons to Human Brain

Wlodzimierz Klonowski, E Olejarczyk, R Stepien

Cellular separation by dielectrophoresis

Josep Samitier, R Casanella, O Ruiz, M Carmona, A Juárez, J Bausells, A Errachid 
Potentiometric method for Triglycerides Determination

Dorota G Pijanowska, W Torbicz

Design of a urethral multi-electrode impedance probe

Jacques Jossinet, Emmanuel Marry

Analysis and Interpretation of Complex HPLC/MS Spectra for Drug Discovery

Huiru (Jane) Zheng, S McClean, P C Ojha, N D Black, J G Hughes, C Shaw

\section{Cardiovascular System}

Multi Layer Perceptron for the Prediction of Ventricular Repolarisation in Function of the Changes of Heart Rate

Rajai El Dajani, M Miquel, M C Forlini, P Maison-Blanche, J Fayn, P Rubel

Non-invasive analysis of haemodynamics in adolescents at rest and during exercise

Koen Matthys, Patrick Segers, Henri Verhaaren, Pascal Verdonck

Pulse Wave Velocity Measurement - The Deformation of Arterial Wall Incurred by Pulsatile Flow

David Leitermann, Lubomír Poušek, Petr Volhejn, Michal Tota, Svatava Konvi ková

A method of left heart ventricle contractility investigation

Juliusz L Kulikowski, Malgorzata Przytulska, Diana Wierzbicka

An Implantable Monophasic/Biphasic Atrial Defibrillation System Using Transcutaneous RF Power

Delivery

Jose A Santos, G Manoharan, N E Evans, J McAnderson, B J Kidawi, J D Allen, A A Adgey

A new approach to the holter events classification based on application of wavelet neural network

Ewaryst Tkacz, A Wrze niowski, P Kostka

Expert and Decision Support Systems

Automated Explanation of Attribute Relevance in Decision-Tree Induction

David McSherry

Blood dynamics control in anaesthesia by complex systems engineering

Aldo Esposito, P Costa, M Magliulo

Prediction models for the design of neural networks for myocardial infarction classification: A genetic programming approach

Jesus A Lopez, C D Nugent, A E Smith, N D Black

A computer-based training system for breast fine needle aspiration cytology.

James Diamond, Neil H Anderson, Deborah Thompson, Peter H Bartels, Peter W Hamilton

Continuous Wavelet Transforms reveal the rich structure of ventricular fibrillation

Paul Addison, James N Watson, Gareth R Clegg, Colin E Robertson, Michael Holzer, Fritz Sterz

Rehabilitation

From medical specifications to switching control implementation for a training and rehabilitation machine for the lower limbs

Janan Zaytoon, L Afilal, S Moughamir, N Manamanni 
Combined magnetic and electric stimulation of peroneal nerve

Eugene Coyle, Prof Annaraoi de Paor, Dr Carl Murray, Mr P Murray, D Curley

Robotic orthosis improves treadmill training of paraplegic patients

Gery Colombo, Reinhard Schreier, Volker Dietz

Influence of walking speed, stride length and posture on ground reaction vertical force during human gait

Julio Cesar Politti, Xavier Savatier, Jean-Yves Ertaud

Responsibilities and involvement of players in the development of successful medical products

Chris J Snijders, I P M Griffioen-van Dijk, E Vlaaderen, C D Augustijn

Instrumentation and VR

Study of Magnetic Three-Dimensional Localizer for Endoscope

Huiru (Jane) Zheng, D Lin, X Chen, J G Hughes, N D Black

PathFinder: a new Image Guided Robot for Neurosurgery

Patrick A Finlay

Instrumentation and algorithms for monitoring cognitive task performance

Paul J McCullagh, R Howard, Lim Ai Lian, C Misir

Application of CNC Milling and Reverse Engineering for the Manufacture of Titanium Cranioplasty Implants

Wesley McKnight, J Winder, B Lewis

The idea of virtual lungs application to ventilatory support testing

Maciej Guc, T Golczewski, M Kozarski, M Darowski

\section{Saturday 5 May 2001}

\section{$\underline{\text { Plenary }}$}

\section{Professor Michael Brady}

Professor of Information Engineering, University of Oxford

Image Analysis for the Diagnosis and Treatment of Breast Cancer, Quantitative Analysis of Cardiac Ultrasound and Degenerative Brain Disease

\section{Professor David Hawkes}

Guy's Kings and St Thomas' Hospitals Medical Schools, London

Image Registration, including non rigid applications

\section{Dr Andrew Barr}

Director, Marturion Ltd

Innovative Medical Instrumentation: an Industrial Perspective 


\section{$\underline{\text { Scientific Sessions }}$}

Telemedicine

A Framework to Support 3D Telemedicine Applications

Heather Sayers, S Wilson, M D J McNeill

Development of a High-Performance ISDN to ATM Telemedicine Gateway in Support of the NCI All Ireland Cancer Consortium

Kenneth M Kempner, D Chow, J E Elson, F S Govern, M E Steele, R L Martino

A compression-decompression client-server architecture supporting the progressive transmission of medical images included in web-documents

A Salomie, R Deklerck, J Cornelis

Computer Supported Collaborative Medical Diagnosis

Hyxia Villegas, Guillermo Montilla, Ana Aguilera, Basel Solaiman, Raphel Pacheco, Fabian

Cardenas, Jose Quintero, Antonio Bosnjak

Communication Reliability in Home-Care Telemetry using the $1800 \mathrm{MHz}$ GSM Network

Stelios Troulis, N E Evans, W G Scanlon

A New image Compression Method for Telemedicine Using Statistical Characteristics of Wavelet

Coefficients

Hou Wensheng, Wu Baoming, Peng Chenlin

Cardiovascular Biomechanics

The Effects of Arterial Wall Remodelling on the Wall Shear Stress Distributions in Vascular Bypass Grafts

Thomas O'Brien, Michael Walsh, Tim McGloughlin

Mathematical model of the cardiovascular mechanics

Alexander Martynenko, B Kantor, M Yabluchansky

Finite element analysis to quantify tissue prolapse within three designs of cardiovascular stents

Caitriona Lally, F Dolan, P J Prendergast, T C Lee, D Quinn

Application of Neural Networks to flexible solid state Ion Selective Sensor Arrays for the Detection of Myocardial Ischemia

Norbert Pilz, Mark Hyland, James McLaughlin, Eric McAdams

A completely magnetically Ievitated Axial-Flow Blood Pump: results from pre-clinical applications

Johannes Müller, Ali Kilic, Yo-gou Weng, Peter Nüsser, Hans-Erhard Peters, Kurt Graichen, Andreas

Arndt, Werner Neumann, Georg Konstas, Jörg Müller, Hendrik Heinze, Jan Hoffmann, Tobias

Merkel, Conrad Kauffeldt, Peter Göttel, Frank Deus, Ines Goebel, Roland Hetzer

Experimental Evaluation of the Migration of Aortic Stent Grafts

Liam Morris, Timothy McGloughlin, P Delasus 
Biomedical Processing and Modelling

Application of Bioimpedance to in vivo breast cancer detection

Nicolas Chauveau, P Martel, S Freitas, B Rigaud, J P Morucci

Determination of EEG activity propagation during voluntary finger movement

Katarzyna J Blinowska, J Ginter Jr, M Kami ski

In vivo measurement of the skull conductivity: EIT versus SEP/SEF

Sonia Isabel Gonçalves, J C de Munck, J P A Verbunt

Automatic Detection of Sleep Stages using the EEG

Peter Van Hese, W Philips, J De Koninck, R Van de Walle, I Lemahieu

Mathematical model of autonomic nervous systems

Alexander Martynenko, M Yabluchansky, B Kantor

Construction of a model of the torso for ECG problems based on CAD tools and images of the human body

Cesar Navarro, J Anderson, J Allen, J Toro, J Riddell, A A J Adgey

Technology for People with a Disability

Espastics Filtering Interface for Technical Aids Switches. A hardware approach

Joqauin Roca Dorda, J Roca Jr, A Mateo, J A Villarejo

Tele-homecare in an urban area utilising commercially available technology

Suzanne Martin

Phone Communication by Means of Synthetic Speech for Deaf-Mute People

Darius Wloskowicz, K Lukaszewicz, K W Radecki

Creative Interfacing - The Development of appropriate assistive technologies for real-time music

performance

Michelle McCormack, C D Nugent, R J Davis, N D Black

ESOT Radio frequency beacon systems as the mobility aid for the blind

Konrad Lukaszewicz, J L Kulikowski, D Wloskowicz, K W Radecki, W Kazubski, T Buczkowski

Bone and Joint Biomechanics

Changing of the micro-mechanical properties of bone after x-ray irradiation

Hans-Joachim Hein, I Eckardt, S Henning, F Syrowatka

Microcrack Accumulation during Fatigue Testing of Compact Bone

Fergal J O'Brien, D Taylor, Clive T Lee

Hardness and elasticity modulus of bone compartments of the femur head measure by

microindentation

Hans-Joachim Hein, R Wolff, W Fräenzel, P Grau

Multiaxial Fatigue of acrylic bone cement

Patrick Prendergast, B P Murphy

Reconstruction of zygomas with medical image based, custom made PMMA implants

Geert Jans, J Vander Sloten, R Gobin, G Van der Perre, M Mommaerts, K Wouters 
Cardiovascular Imaging and Instrumentation

New Method of Transesopheageal Signal Filtering During Noninvasive Electrophysiological Study of the Heart Conductive System

Kazimierz Peczalski, D Wojciechowski, Z Niedbalski, M Kowalewski, P Sionek, G Skoczylas, M

Stopczyk

Application of Optoelectronic Methods in Monitoring of Chemical Sympathectomy

Piotr Lukasiewicz, A Liebert, W Raciborski, W Staszkiewicz, R Maniewski

Near Infrared Spectroscopy for Monitoring of Cerebral Oxygention During Carotid Surgery

Roman Maniewski, A Liebert, A Gabrusiewicz, A Zbie , D Gawlikowska, W Staszkiewicz

Scanning Electrical Conductivity Interfaces by Means of Ultrasound in Magnetic Field

A Montalibet, J Jossinet, A Matias

Design of Speckle Denoising Filter using Wavelet-Based Thresholding for Medical Imaging

Application

Su Cheol Kang

\section{$\underline{\text { Posters }}$}

Health Information Systems

Coronary Tree Modelling with Iterative Function Systems using a genetic algorithm

Jesus A Lopez, C D Nugent, N D Black

An electro-oculogram based human-computer interface for the disabled

Jesus A Lopez, N D Black, C D Nugent, Kl Ziri-Castro

A human-computer interface to assist in the development of musical devices for physically impaired students

Chris Nugent, R J Davies, N D Black, M McCormack

Quantum Informatics

Mark McCartney, D Glass

Optimization of the Thermal Protective Clothing using a Knowledge Bank Concept and a Learning

Expert System

Laure Schwenzfeier, B Warme-Janville, G Delhomme, A Dittmar

Image Display Management for Telecare Applications

Fionn Murtagh, Mohsen Farid

The Learning and Teaching Support Network - Promoting Innovation and Good Practice in Health and Medical Informatics

Sylvia Alexander, Margaret Sills, Megan Quentin-Baxter

A neural network prediction model to assist in the design of myocardial infarction classifiers

Chris D Nugent, J A Lopez, A E Smith, N D Black

Barriers To Evidence Based Practice - The dependence on medical informatics

George Kernohan

Home Control System for the Social Integration of Disabled People

Joaquin Roca Dorda, Jose A Vera, Manuel Jimenez 


\section{Bioengineering}

A comparative study of three techniques for $Q R S$ cancellation in the ECG Omar J Escalona, M A Diaz, A I Hernández, F Mora

Medical image based personalised tibial component: biomechanical evaluation Veerle Pattijn, J Vander Sloten, R Van Audekercke, B Swaelens, G Isaac

Medical Imaging \& Instrumentation

The Design of a Compact, Multi-element Test Object for Use in Monte Carlo calculations in diagnostic radiology

Jing Ning, K Cranley, S McClean

Medical engineering technologies for diagnosis and correction of higher mental function in children and adolescents

Evgeni Matveev, V A Viktorov, G I Kavalerov

DSC (Digital Scan Converter) - Error-Free Beamforming Method for Ultrasound Imaging

JaeSub Hwang, Tai-kyong Song

Application of indicator dilution method for non-invasive cardiac output measurement

Maciej Guc, Artur Szczepanski, Jacek Jastrzebski, Tadeusz Palko, Andrzej Ksiazkiewicz

Limits of spline interpolation in event related potential mapping

Nicolas Chauveau, X Franceries, B Doyon, B Rigaud, J P Morucci, P Celsis

Selected algorithms for the computer analysis of microscope scans in the system for early detection of the urinary bladder cancer

Pawel Jaszczak, A Dulewicz, A Nechaj, D Pietka

Digital HDTV for Improved Image Quality of Endoscopes

Peter Niederer, J Häfliger, P Blessing, Y Lehareinger, D Doswald, N Felber

The New Approach to Evaluation of Vasovagal Syncope Patients Treated by Pacing of the Heart

Kazimierz, Peczalski, Darius Wojciechowski, Piotr Sionek, Marek Kowalewski

Localization of Component Parts of Retinal Images

Fionn Murtagh, Mohsen Farid 